\title{
ANALISA SOFTWARE GRBL CONTROLLER UNTUK MESIN MINI CNC PLOTTER 3 - AXIS DENGAN MENGGUNAKAN MIKRO KONTROLER ATMEGA 328
}

\author{
Herwan Suwandi ${ }^{1}$, Septian Tri Setianto ${ }^{2}$ \\ ${ }^{1,2)}$ Universitas Wanita Internationala \\ herwans70@gmail.com
}

\begin{abstract}
ABSTRAK
Dalam sebuah industri khususnya manufaktur terdapat mesin CNC dengan berbagai macam jenis seperti Milling, Frais, Bubut dan banyak lagi yang berfungsi untuk membuat suatu bahan mentah dari besi yang di ukir menjadi suatu barang yang berguna bagi kebutuhan manusia, yang biasanya terdiri dari 2 hingga 6 axis. Penulis membuat prototype mesin mini CNC plotter 3 - axis dari bahan standar dengan software yang opensource sehingga seluruh masyarakat bisa mencoba mempelajari mesin CNC tersebut, adapun software yang akan digunakan sebagai kontrol dari mesin mini CNC plotter tersebut adalah GRBL Controller dan juga mesin ini menggabungkan software aplikasi inscape yang berguna sebagai converter menjadi GCode.Dalam penulisan penelitian ini metode penelitian yang digunakan penulis yaitu dengan melakukan metode kuantitatif yang akan menjelaskan sistem dari software mesin mini CNC plotter 3 - axis sehingga menjadi satu kesatuan sistem yang akan dijelaskan dari data - data G-Code yang sudah dibuat.
\end{abstract}

kata kunci : GRBL Controller, CNC, plotter, axis, G-Code.

\begin{abstract}
In an industry manufacturing in particular there are CNC machines wide range of types such as Milling, Frais, Lathe and much more to make a raw material of iron in carved into an item that is useful for human needs, which usually consists of 2 up to 6 axis. The author made a prototype machine mini 3 - axis CNC plotter from standard materials with opensource software so that the whole community can try to learn CNC machines, as for the software that will be used as the control of the engine mini CNC plotter it was also the machines GRBL controller combines software applications useful as inscape converter into G-Code.In the writing of this research method that are used by authors do quantitative methods that will describe the ststem from the software machine mini 3 - axis CNC plotter so that becomes a single unit system to be described from data $G$-Code that is already made.
\end{abstract}

key word : CNC, plotter, axis, software, G-Code.

\section{PENDAHULUAN}

Dunia industri khususnya manufaktur, terdapat mesin yang bernama CNC. Berbagai macam jenis CNC yang terdapat pada industri manufaktur yaitu CNC Milling, Frais, Bubut dan banyak lagi. Mesin CNC tersebut harganya sangat ahal dan hanya industri manufaktur yang memiliki modal besar yang hanya bisa menggunakan mesin $\mathrm{CNC}$ tersebut. CNC tersebut berfungsi untuk membuat suatu bahan mentah dari besi yang di ukir menjadi suatu barang yang berguna bagi kebutuhan manusia, yang biasanya terdiri dari 2 hingga 6 axis.

Fungsi CNC dalam hal ini lebih banyak menggantikan pekerjaan operator dalam mesin perkakas konvensional, misalnya dalam pekerjaan setting tools atau mengatur gerakan pahat sampai pada posisi sesuai. Penulis mencoba membuat prototype mesin mini CNC plotter 3 - axis dari bahan standar dengan harga yang relatif murah dan juga dengan software yang gratis sehingga seluruh masyarakat bisa mencoba mempelajari mesin CNC tersebut.

Software yang akan digunakan sebagai kontrol dari mesin mini CNC plotter tersebut adalah GRBL Controller yang referensinya didapat dari beberapa sumber refrensi. Dan mesin ini menggunakan software aplikasi inscape yang berguna sebagai converter menjadi G-Code. Dari sana Penulis mencoba mengaplikasikan dan meneliti suatu software GRBL Controller yang digunakan dan aplikasi inkscape untuk mesin mini CNC plotter yang akan Penulis ajukan sebagai 
bahan untukpenelitian ini Penulis yang berjudul "Mengaplikasikan dan Analisa Software GRBL Controller Untuk Mesin Mini CNC Plotter 3 - Axis Dengan Menggunakan Mikrokontroler ATMega 328"

Tujuan dibuatnya penelitian ini adalah Untuk mengetahui langkah - langkah dari menghubungkan mesin mini CNC plotter tersebut ke komputer kemudian mengetahui cara untuk membuat koding G-Code dari aplikasi inkscape yang digunakan. Untuk mengetahui langkah - langkah dari pengerjaan software GRBL Controller yang digunakan sebagai kontrol dari mesin mini CNC plotter 3 - axis tersebut.

\section{METODE PENELITIAN}

\section{A. Objek Penelitian}

Tempat penelitian yang Penulis gunakan adalah laboratorium jurusan fisika International Women University yang bertempat tinggal di jalan Ahmad Yani No. 18-20, Malabar, Lengkong, kota Bandung, Jawa Barat.

\section{B. Metode Penelitian}

Metode penelitian yang digunakan dalam penelitian ini mengarah kepada tujuan yang akan dicapai. Sehingga membutuhkan desain penelitian yang baik dan cocok untuk mengumpulkan data-data yang diperlukan dalam penyusunan ini.

\section{1) Desain Penelitian}

Desain penelitian yang digunakan penulis dalam melakukan penelitian ini menggunakan metode penelitian $i$ analisis deskriptif. Dimana metode penelitian analisis deskriptif ini dilakukan dengan tujuan mendapatkan data yang sebenarnya dan selengkaplengkapnya untuk membuat sistem yang akan dibangun. Untuk melakukan penelitian ini penulis menentukan terlebih dahulu objek penelitian yang dituju untuk menjadi fokus utama, yaitu software GRBL controller pada mesin mini CNC dan penggunaan mikrokontroler Atmega 328. Untuk Memenuhi Penelitian, Penulis Mengumpulkan Data Yang Diperlukan Dengan Melakukan wawancara, dan mengumpulkan data-data tertulis yang dibutuhkan untuk penelitian ini berlangsung.

2) Metode Pendekatan dan Pengembangan Sistem Metode pendekatan sistem merupakan salah satu cara penyelesaian persoalan yang dimulai dengan dilakukannya identifikasi terhadap adanya sejumlah kebutuhan-kebutuhan, sehingga dapat menghasilkan suatu operasi dari sistem yang dianggap efektif. Sedangkan metode pengembangan sistem terdiri dari sederetan kegitan yang dapat dikelompokkan menjadi beberapa tahapan, yang membantu kita dalam pengembangan sistem. Metode pengembangan sistem yang di gunakan penulis dalam penelitian berikut adalah dengan metode development yang dihasilkan dari alat yang sudah ada dikembangkan lagi menjadi alat terbaharukan.

3) Pemilihan Software Yang Digunakan Hal pertama yang akan dilakukan adalah pemilihan software, software yang sangat berpengaruh terhadap jalan atau tidaknya mesin mini CNC plotter adalah software GRBL controller. GRBL controller berperan penting sebagai kontrol mesin mini CNC plotter.

\section{HASIL DAN PEMBAHASAN}

A. Hasil Penelitian Gambar Persegi Dari GRBL Controller

Pada bagian ini Penulis akan menjelaskan tentang pergerakan dari hasil G-Code yang dijalankan. Sebelumnya pada bab 3 Penulis sudah menjelaskan tentang cara pembuatan desain sketsa gambar persegi sehingga menjadi program G-Code yang akan dijalankan oleh mesin mini CNC plotter 3 - axis. Selanjutnya Penulis akan menjelaskan hasil program tersebut sehingga menjadi pergerakan persegi pada mesin melalui tabel berikut.

Tabel 1. Program G-Code Persegi Secara

\begin{tabular}{|c|c|c|c|c|c|}
\hline $\mathbf{N}$ & G/M & $\mathbf{X}$ & $\mathbf{Y}$ & $\mathbf{Z}$ & $\mathbf{F}$ \\
\hline 01 & G21 & 0 & 0 & 0 & \\
\hline 02 & G90 & 0 & 0 & 0 & \\
\hline 03 & G92 & 0 & 0 & 0 & \\
\hline 04 & G01 & -9.95 & 9.95 & 0 & 3500 \\
\hline 05 & G01 & 0 & 0 & -10 & 3500 \\
\hline 06 & G01 & 9.95 & 9.95 & -10 & 3500 \\
\hline 07 & G01 & 9.95 & -9.95 & -10 & 3500 \\
\hline 08 & G01 & -9.95 & -9.95 & -10 & 3500 \\
\hline 09 & G01 & -9.95 & 9.95 & -10 & 3500 \\
\hline 10 & G01 & -9.95 & 9.95 & 0 & 3500 \\
\hline 11 & G00 & 0 & 0 & 0 & 3500 \\
\hline
\end{tabular}


Tabel diatas adalah program G-Code hasil dari inkscape untuk membuat persegi yang sudah di sederhanakan. Berdasarkan tabel tersebut dapat dijelaskan sistem pengerjaan mesin melalui ketiga sumbu X, Y, dan Z. Pada saat blok no 1, program koding G21 dijalankan sebagai kepala program yang berfungsi untuk konversi nilai satuan menjadi milimeter. Kepala program selanjutnya adalah blok no 2 ada G90 yang berfungsi untuk perintah sistem koordinat pengerjaan secara absolut.

Pada kepala program terakhir pada blok no 3 ada sistem perinta G92 dengan sumbu $\mathrm{X}, \mathrm{Y}$, dan $\mathrm{Z}$ sebesar 0 yang berfungsi sebagai zeroposition atau pencatat penetapan mulai pengerjaan, pada pengerjaan persegi ini zeroposition terletak di tengah bidang pengerjaan. Pada blok no 4 hingga 10 adalah badan program yang akan menjalankan mesin mini CNC plotter menjadi gambar persegi. Pada blok no 4 - 10 terdapat kode program G1 yang berarti pergerakan dengan penyayatan mata pulpen.

Pada bagian ini hasil yang terjadi berbeda dari nilai yang sudah ditentukan dari awal. Pada bagian G-Code sumbu $\mathrm{X}$ maupun $\mathrm{Y}$, nilai menjadi $19.9 \mathrm{~mm}$ yang seharusnya sebesar $20 \mathrm{~mm}$ dikarenakan adanya penambahan dari garis desain persegi. Besar dari garis tersebut dihitung oleh apikasi inkscape sebesar $0.05 \mathrm{~mm}$, sehingga ketika pergerakan mesin secara vertikal maupun horizontal atau terhadap sumbu $\mathrm{X}$ maupun sumbu Y terdapat 2 kali besar garis sehingga nilai yang awalnya $20 \mathrm{~mm}$ menjadi $19.9 \mathrm{~mm}$ dikarenakan oleh pengurangan dari 2 kali besar garis atau bisa disebut dengan pengerjaan di dalam atau pengerjaan inside.

Tetapi hasil pengerjaan gambar persegi yang dibuat oleh mesin mini CNC plotter 3 axis tetap $20 \mathrm{~mm}$ dengan tidak adanya gerakan menyimpang dari mesin.

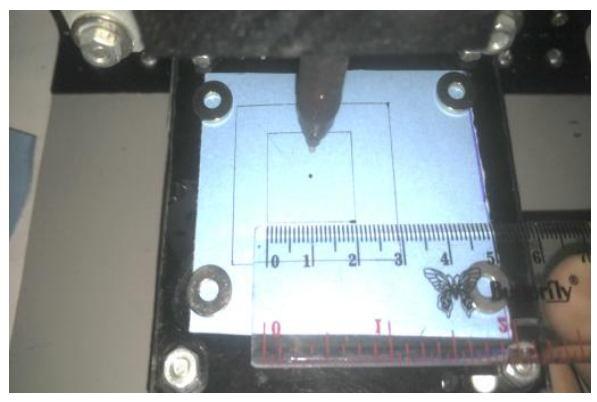

Gambar 1. Perhitungan Persegi Pada Sumbu $\mathrm{X}$
Dapat dilihat pada gambar 1 perhitungan besar panjang garis terhadap sumbu $\mathrm{X}$ yang digunakan sebesar $20 \mathrm{~mm}$ dengan tidak adanya penyimpangan gerakan karena tegak lurus terhadap arah horizontal.

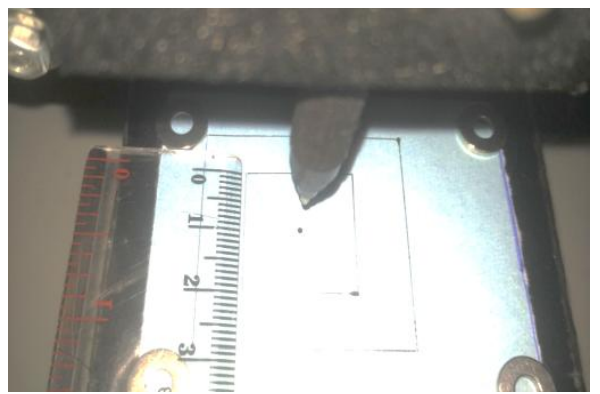

Gambar 2. Perhitungan Persegi Pada Sumbu $\mathrm{Y}$

Sama seperti dengan sumbu X, sumbu Y pun menghasilkan gambar sebesar $20 \mathrm{~mm}$ bisa dilihat dari gambar 2 .

Dari analisa pembahasan tersebut didapatkan rumus persentasi sebagai berikut :

Total Gerakan Yang Tidak Menyimpang

Total langkah pengerjaan

$$
\begin{gathered}
\frac{4}{4} \times 100 \% \\
100 \%
\end{gathered}
$$

Menjelaskan bahwa hasil dari pembuatan gambar persegi yang dibuat dari proses pengerjaan software yang dijalankan oleh GRBL controller yang di analisa memiliki keakuratan $100 \%$.

\section{B. Hasil Penelitian Gambar Lingkaran Program G1}

Pada hal ini hasil program dari inkscape akan dimasukkan ke dalam tabel sehingga akan menjadi seperti berikut.

Tabel 2. Hasil Program Gambar Lingkaran

\begin{tabular}{|c|c|c|c|c|c|}
\hline $\mathbf{N}$ & G/M & $\mathbf{X}$ & $\mathbf{Y}$ & $\mathbf{Z}$ & $\mathbf{F}$ \\
\hline 01 & G21 & 0 & 0 & 0 & \\
\hline 02 & G90 & 0 & 0 & 0 & \\
\hline 03 & G92 & 0 & 0 & 0 & \\
\hline 04 & G1 & 9.95 & 0 & 0 & 3500 \\
\hline 05 & G1 & 0 & 0 & -10 & 3500 \\
\hline 06 & G1 & 9.61 & -2.6 & -10 & 3500 \\
\hline 07 & G1 & 8.62 & -4.98 & -10 & 3500 \\
\hline 08 & G1 & 7.05 & -7.02 & -10 & 3500 \\
\hline 09 & G1 & 4.98 & -8.62 & -10 & 3500 \\
\hline 10 & G1 & 2.55 & -9.62 & -10 & 3500 \\
\hline 11 & G1 & 0 & -9.95 & -10 & 3500 \\
\hline 12 & G1 & -2.55 & -9.62 & -10 & 3500 \\
\hline 13 & G1 & -4.98 & -8.62 & -10 & 3500 \\
\hline
\end{tabular}




\begin{tabular}{|c|c|c|c|c|c|}
\hline 14 & G1 & -7.05 & -7.02 & -10 & 3500 \\
\hline 15 & G1 & -8.62 & -4.98 & -10 & 3500 \\
\hline 16 & G1 & -9.61 & -2.6 & -10 & 3500 \\
\hline 17 & G1 & -9.95 & 0 & -10 & 3500 \\
\hline 18 & G1 & -9.61 & 2.6 & -10 & 3500 \\
\hline 19 & G1 & -8.62 & 4.98 & -10 & 3500 \\
\hline 20 & G1 & -7.05 & 7.02 & -10 & 3500 \\
\hline 21 & G1 & -4.98 & 8.62 & -10 & 3500 \\
\hline 22 & G1 & -2.55 & 9.62 & -10 & 3500 \\
\hline 23 & G1 & 0 & 9.95 & -10 & 3500 \\
\hline 24 & G1 & 2.55 & 9.62 & -10 & 3500 \\
\hline 25 & G1 & 4.98 & 8.62 & -10 & 3500 \\
\hline 26 & G1 & 7.05 & 7.02 & -10 & 3500 \\
\hline 27 & G1 & 8.62 & 4.98 & -10 & 3500 \\
\hline 28 & G1 & 9.61 & 2.6 & -10 & 3500 \\
\hline 29 & G1 & 9.95 & 0 & -10 & 3500 \\
\hline 30 & G1 & 9.95 & 0 & 0 & 3500 \\
\hline 31 & G0 & 0 & 0 & 0 & 3500 \\
\hline
\end{tabular}

Dari tabel diatas dapat diteliti bahwa pergerakan gambar lingkaran menggunakan program G1 memerlukan 25 langkah pengerjaan sehingga menjadikan gambar berbentuk lingkaran.Langkah pengerjaan lingkaran dari G1 memiliki sedikit kesamaan seperti pengerjaan pada gambar persegi dengan menggunakan metode absolut dan memiliki zeroposition yang terletak di tengah.

Pada gambar hasil pengerjaan dari desain lingkaran dengan program G1 memiliki sedikit penyimpangan pergerakan pada gambar. Gambar yang dihasilkan tidak sempurna karena ke tidak mampu program G-Code memberikan kecepatan aliran data yang tepat ke sistem mikrokontroler ATMega 328 pada mesin sehingga adanya penyimpangan pergerakan yang dilakukan oleh mesin mini CNC plotter 3 - axis tersebut.

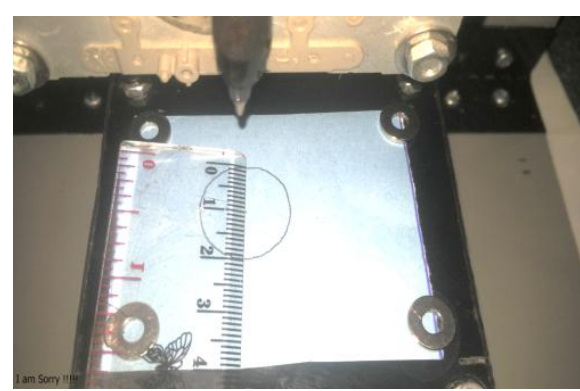

Gambar 3. Perhitungan Lingkaran Dengan Program G1

Bisa dilihat pada gambar 3 tersebut bahwa diameter dari gambar lingkaran tersebut sebesar $20 \mathrm{~mm}$, itu membuktikan bahwa besar pergerakan yang dihasilkan oleh hardware sudah sejalan dengan software. Tetapi mengalami sedikit penyimpangan pengerjaan dengan kemungkinan rata - rata berkisar $0.08 \mathrm{~mm}$ setiap satu step langkah pengerjaan. membuktikan bahwa ketika pengerjaan secara diagonal atau radius memiliki penyimpangan pergerakan rata rata sebesar $0.08 \mathrm{~mm}$.

\section{Hasil Penelitian Gambar Lingkaran Program G2}

Hasil gambar lingkaran dengan menggunakan program G2 memiliki kesamaan dan ketepatan pada pengerjaan dengan program G1, tetapi memiliki penyimpangan lebih kecil dari program G1 sekitar rata - rata $0.5 \mathrm{~mm}$. Hasil program dari inkscape dapat dibuat tabel seperti berikut.

Tabel 3. Hasil Program Gambar Lingkaran G2

\begin{tabular}{|c|c|c|c|c|c|}
\hline $\mathrm{N}$ & $\mathrm{G} / \mathrm{M}$ & $\begin{array}{c}\mathrm{X} \\
\mathrm{I}\end{array}$ & $\begin{array}{c}\mathrm{Y} \\
\mathrm{J}\end{array}$ & $\mathrm{Z}$ & $\mathrm{F}$ \\
\hline 1 & $\mathrm{G} 21$ & 0 & 0 & 0 & \\
\hline 2 & $\mathrm{G} 90$ & 0 & 0 & 0 & \\
\hline 3 & $\mathrm{G} 92$ & 0 & 0 & 0 & \\
\hline 4 & $\mathrm{G} 0$ & 9.95 & 0 & 0 & 3500 \\
\hline 5 & $\mathrm{G} 1$ & 9.95 & 0 & -10 & 3500 \\
\hline 6 & $\mathrm{G} 2$ & $\begin{array}{c}0 \\
-9.95\end{array}$ & $\begin{array}{c}-9.95 \\
0\end{array}$ & -10 & 3500 \\
\hline 7 & $\mathrm{G} 2$ & $\begin{array}{c}-9.95 \\
0\end{array}$ & $\begin{array}{c}0 \\
9.95\end{array}$ & -10 & 3500 \\
\hline 8 & $\mathrm{G} 2$ & 0 & 9.95 & -10 & 3500 \\
& & 9.95 & 0 & & \\
\hline 9 & $\mathrm{G} 2$ & $\begin{array}{c}9.95 \\
0\end{array}$ & $\begin{array}{c}0 \\
-9.95\end{array}$ & -10 & 3500 \\
\hline 10 & $\mathrm{G} 0$ & 0 & 0 & 0 & \\
\hline
\end{tabular}

Dari tabel ini dapat dibuat langkah pengerjaan dengan menggunakan program dari G2 yang berfungsi untuk penyayatan menggunakan radius searah dengan jarum jam, sehingga langkah yang dilakukan dalam pengerjaan sebesar 4 langkah saja. Pada kepala program memiliki kesamaan untuk seluruh program yang dikerjakan.Pada blok no 4 menggunakan program G0 pergerakan dengan tanpa penyayatan dengan kode program sumbu $X$ mengarah ke 9.95 dan sumbu Y tidak mengalami perubahan.Pada blok no 5 mata pulpen bergerak ke bawah menyentuh permukaan kertas sebesar $10 \mathrm{~mm}$. Dan pengerjaan terakhir adalah pada blok no 9 yang bergerak ke arah sumbu $\mathrm{X}$ dan $\mathrm{Y}$ ke titik 9.95 dan 0 dengan I dan $\mathbf{J}$ sebesar 0 dan - 
9.95. Karena tidak adanya jarak pada sumbu $\mathrm{X}$ terhadap titik pusat lingkaran dan jarak pada sumbu Y terhadap titik pusat lingkaran sebesar $9.95 \mathrm{~mm}$ ke arah bawah sehingga menghasilkan -9.95. Selanjutnya di akhir program dibuat kembali ke titik awal.

Pada pergerakan diakhir gambar dapat dilihat sedikit perbedaan yang tidak dapat dihitung karena terlalu kecil. Berarti ada satu pergerakan yang menyimpang dari 4 langkah yang membuat gambar lingkaran sehingga didapatkan rumus.

Total Gerakan Yang Tidak Menyimpang

$$
\begin{gathered}
\text { Total langkah pengerjaan } \\
\frac{3}{4} \times 100 \% \\
75 \%
\end{gathered}
$$

Menjelaskan bahwa hasil dari pembuatan gambar lingkaran dengan menggunakan program G2 yang dibuat dari proses pengerjaan software yang dijalankan oleh GRBL controller yang di analisa memiliki keakuratan $75 \%$.

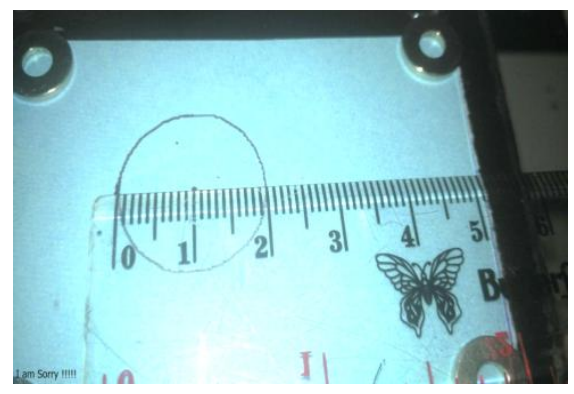

Gambar 4. Perhitungan Lingkaran Dengan Program G2

\section{Hasil Penelitian Gambar Bintang Dari GRBL Controller}

Pada penelitian akhir kali ini Penulis akan mencoba membuat gambar berbentuk bintang dengan hasil program G-Code yang dijadikan tabel sebagai berikut .

Tabel 4. Hasil Program Gambar Bintang

\begin{tabular}{|c|c|c|c|c|c|}
\hline $\mathbf{N}$ & G/M & $\mathbf{X}$ & $\mathbf{Y}$ & $\mathbf{Z}$ & $\mathbf{F}$ \\
\hline 1 & G21 & 0 & 0 & 0 & \\
\hline 2 & G90 & 0 & 0 & 0 & \\
\hline 3 & G92 & 0 & 0 & 0 & \\
\hline 4 & G1 & -0.02 & 9.95 & 0 & 3500 \\
\hline 5 & G1 & -0.02 & 9.95 & -10 & 3500 \\
\hline 6 & G1 & 3.07 & 3.42 & -10 & 3500 \\
\hline
\end{tabular}

\begin{tabular}{|c|c|c|c|c|c|}
\hline 7 & G1 & 9.95 & 2.39 & -10 & 3500 \\
\hline 8 & G1 & 4.99 & -2.72 & -10 & 3500 \\
\hline 9 & G1 & 6.19 & -9.91 & -10 & 3500 \\
\hline 10 & G1 & 0.03 & -6.53 & -10 & 3500 \\
\hline 11 & G1 & -6.11 & -9.95 & -10 & 3500 \\
\hline 12 & G1 & -4.96 & -2.75 & -10 & 3500 \\
\hline 13 & G1 & -9.95 & 2.32 & -10 & 3500 \\
\hline 14 & G1 & -3.08 & 3.4 & -10 & 3500 \\
\hline 15 & G1 & -0.02 & 9.95 & -10 & 3500 \\
\hline 16 & G1 & -0.02 & 9.95 & 0 & 3500 \\
\hline 17 & G0 & 0 & 0 & 0 & 3500 \\
\hline
\end{tabular}

Pada kepala program Penulis menggunakan G21, G90, G92 yg berfungsi untuk pengerjaan secara absolut dan menentukan titik zeroposition di tengah.

Selanjutnya pada badan program blok no 4 menggunakan $\mathrm{G} 1$ dengan sumbu $\mathrm{X}$ dan $\mathrm{Y}$ mengarah ke titik -0.02 dan 9.95 tanpa penyayatan. Pada blok no 5 adalah penurunan pada sumbu $\mathrm{Z}$ sebesar -10 sehingga mata pulpen turun sebesar $10 \mathrm{~mm}$. Pada blok program no 6 terdapat program G1 dengan sumbu $\mathrm{X}$ dan $\mathrm{Y}$ mengarah ke titik 3.07 dan 3.42 sehingga didapatkan pergerakan pada bidang kertas ke arah bawah secara diagonal sebesar $7.38 \mathrm{~mm}$ dengan menggunakan rumus pitagoras seperti sebagai berikut :

\section{$\sqrt[2]{(\text { Titik Sumbu YAwal - Titik Sumbu Y Akhir })^{2}+\text { Titik Sumbu Y Akhir }^{2}}$ $\sqrt[2]{(9.95-3.42)^{2}+3.42^{2}}$$$
\sqrt[2]{42.6409+11.6964}
$$$$
\sqrt[2]{54.3373}
$$$$
7.38 \mathrm{~mm}
$$

Dengan selanjutnya menggunakan rumus tersebut didapatkan hasil $7.38 \mathrm{~mm}$ disetiap pergerakan diagonal yang dihasilkan untuk membentuk gambar bintang dengan penyimpangan rata - rata sebesar $0.05 \mathrm{~mm}$ yang terjadi oleh pergerakan secara diagonal.

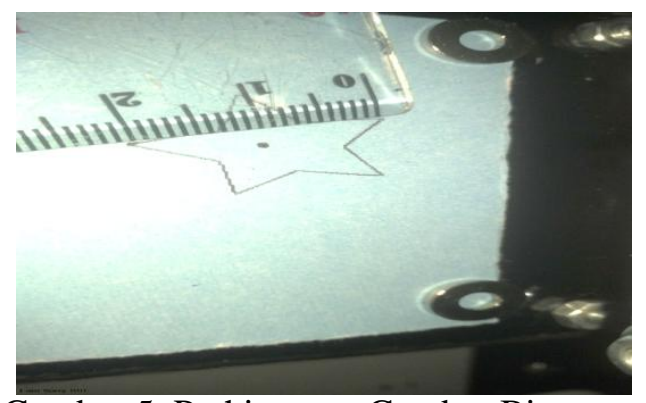

Gambar 5. Perhitungan Gambar Bintang

Dari Gambar diatas didapatkan bahwa hasil tinggi dan besar bitang terhadap sumbu 
$\mathrm{X}$ dan $\mathrm{Y}$ sebesar $20 \mathrm{~mm}$ yang membuktikan bahwa hasil dari hardware dan software sejalan.

\section{E. Hasil Penelitian Gambar Logo InternationalWomenUniversity}

Dengan berbagai kali percobaan hingga mesin tersebut bisa mencapai pengerjaan yang maksimal akhirnya didapatkan percobaan yang hampir mendekati gambar sesungguhnya. Tetapi gambar tersebut tidak teralu sama persis dengan desain yang diinginkan.Dari percobaan tersebut dapat diteliti adalah ukuran bentuk gambar, yang seharusnya dibuat dengan panjang $30 \mathrm{~mm}$ dan lebar $30 \mathrm{~mm}$ menjadi panjang $29.01 \mathrm{~mm}$ mewakili sumbu Y dan $28.16 \mathrm{~mm}$ mewakili sumbu $\mathrm{X}$ dikarenakan terpengaruh dari hasil pengeditan oleh inkscape.

Masih terlalu banyak penyimpangan pengerjaan yang berkisar rata rata $\pm 0.05 \mathrm{~mm}$.

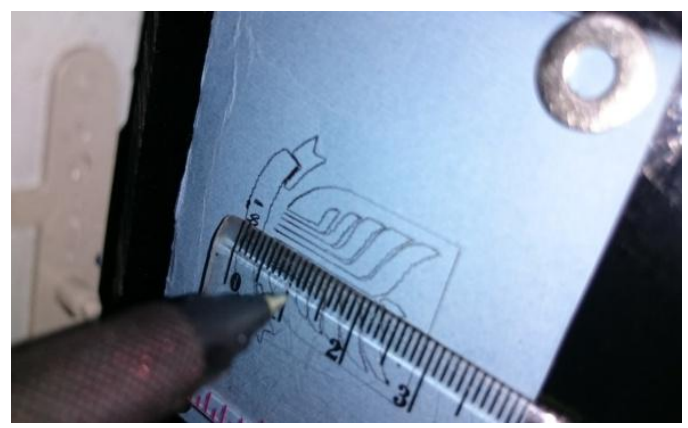

Gambar 6. Perhitungan Panjang Logo IWU

Dari gambar 6 dapat dilihat panjang logo IWU sebesar $20.1 \mathrm{~mm}$ yang didapat dari pertambahan titik yang paling bawah dan atas dari visualizer yang ada di GRBL controller. Gambar 6 Perhitungan Lebar Logo IWU

Dari hasil penelitian tersebut didapatkan lebar dari hasil gambar logo iwu yang dibuat adalah sebesar $28.16 \mathrm{~mm}$ yang didapatkan dari perhitungan yang ada di visualizer yang terletak di GRBL controller. Pada setiap pengerjaan yang panjang pasti ada sedikit penyimpangan pengerjaan yang terjadi, semakin panjang pengerjaan tersebut maka semakin banyak pula penyimpangan dan semakin sedikit keakuratan yang akan dibuat oleh mesin mini CNC plotter 3 - axis tersebut.

\section{KESIMPULAN}

Adapun kesimpulan yang dihasilkan dari skripsi ini yang berjudul mengaplikasikan dan analisa software GRBL Controller untuk mesin mini CNC plotter 3 - axis dengan menggunakan mikrokontroler ATMega 328 adalah :

1. Dari penjelasan di atas kesimpulan dari cara menghubungkan komputer dengan mesin mini CNC plotter tersebut adalah dengan menggunakan USB dan berbagai langkah yang sudah dijelaskan di bab sebelumnya.

2. Cara membuat desain dengan aplikasi inkscape adalah dengan menggunakan tools yang ada di dalam aplikasi inkscape ataupun dengan cara mengambil gambar yg berbentuk .SVG ataupun .PNG

3. Jadi cara menggunakan GRBL controller adalah dengan menghubungkan dahulu alat dengan komputer selanjutnya tinggal di masukkan G-Code yang sudah dibuat.

\section{DAFTAR PUSTAKA}

[1] A, Fauzi, I K. 2011, Mengelola Pelatihan Partisipatif,. Alfabeta, Bandung.

[2] Al-Balushi, Sulaiman M. 2012, "Omani Twelfth Grade Student' Most Common Misconception In Chemistry", Science Educational International.

[3] Arnold, H. 2001, The Recent History of the Machine Tool Industry an the Effects of Technological Change.

[4] Modul BBPLK Bandung. 2015, Memprogram Mesin NC/CNC (Dasar). Bandung

[5] Benjamin, Donna. 2010, Beginning Inkscape, Apres.

[6] Hafid, Burhan. 2015, Proses Produksi Mesin CNC, Universitas Riau.

[7] Madekar,J. R,Kranti. R,Pooja. S,Vikas. 2016, Automatic Mini CNC Machines For PCB Drawing And Drilling.

[8] Prince,Khan. Ansary,Muhsi. Shafwan,Abu. Implementation of Low-Cost CNC Plotter Using Spare Parts.

[9] S, Pressman, Roger. 2002, RPL : Pendekatan Praktisi ( Buku 1 ), ANDI, Yogyakarta.

[10] S, Daulay, Melwin. 2007, Mengenal Hardware-Software dan Pengelolaan Instalasi Komputer, CV. ANDI OFFSET, Yogyakarta. 
[11] Santosa, H. 2012, Apa Itu Arduino, UGM.

[12] Setiawan, Afrie. 2011, 20 Aplikasi Mikrokontroller ATMega 8535 \& ATMega 16 menggunakan BascomAVR, Andi, Yogyakarta.

[13] Smid, P. 2003, CNC Programming Handbook 2nd Edition, Industrial Press Inc, New York.

[14] Wilman, R. Riyan. 2006, Mengenali dan Mengatasi Kerusakan Software Handphone. PT. Kawan Pustaka, Tanggerang.

[15] Yahuza, Rosehan. 2010, Teknologi CNC (Mastercam Book For Windows). Jakarta.

[16] https/github.com/zipmaker/GrblHomin $\mathrm{g} / \mathrm{releases}$.

[17] Download IDE Arduino : https/arduino.cc.

[18] Download Hex Uploader : https/paulkaplan.me/HexUploader.

[19] Download Inkscape https/inkscape.org.

[20] Download XQuartz https/www.xquartz.org/releases/XQuar tz-2.7.11.html.

[21] Download Inkscape Unicorn Master : markerbot.wikidot.com/unicornoutput-for-inkscape. 
Halaman ini sengaja dikosongkan 